\title{
Tobit Model ve Bir Uygulama
}

\section{Şeyma KOÇ ${ }^{1}$ (iD), Mustafa ŞAHİं1(i)}

${ }^{1}$ Kahramanmaraş Sütçü İmam Üniversitesi, Ziraat Fakültesi, Zootekni Bölümü, Kahramanmaraş

$\triangle$ : koçkutlu1@gmail.com

\section{ÖZET}

Bu çalışmada sınırlı bağımlı değişkenli modelleri açıklamada yaygın biçimde kullanılan Tobit Model incelenmiştir. Çalışmanın amacı bağımlı değişkeni sınırlı olan veri setlerinin parametre tahmin basamaklarını hem teorik olarak hem de bir uygulama ile anlatmaya çalışmaktır. Literatür tarama yöntemi kullanılarak tobit model ana çizgileri ile anlatılmış, toplanan bilgiler bir örnek ile sayısallaştırılarak daha anlaşılır hale getirilmiştir. Çalışmanın sonucunda analiz süreçlerinde sürekli ve kesikli karma veri yapısı ile karşılaşan araştırıcılara tobit regresyon modelinin teorisi sunulmuş ve istatistiksel çıkarsama sürecinde Tobit model kullanımı önerilmiştir.

\section{Tobit Model and an Application}

\section{ABSTRACT}

In this study, Tobit Model which is widely used to describe the limited dependent variable models was examined. The aim of the study was to try to explain parameter estimation steps of data sets, which dependent variable is limited, both theoretically and by an application. By using the literature survey method, main lines of Tobit model were explained and the gather information was digitized with a sample to make it more understandable. As a result of the study, the theory of the tobit regression model was presented and the use of the Tobit model was proposed in the statistical inference process.

\section{DOI:10.18016/ksudobil.285929}

\author{
Makale Tarihçesi \\ Received : 15.01.2017 \\ Accepted : 15.03.2017
}

\section{Anahtar Kelimeler}

Sansürlü Veri,

Kırpılmış Veri,

Tobit Analiz

\section{Araştırma Makalesi}

To Cited : Koç Ş, Şahin M 2018. Tobit Model ve Bir Uygulama. KSÜ Tarim ve Doğa Derg 21(1):73-80, DOI:10.18016/ksudobil.285929.

\section{Gíniş̧}

İstatistik biliminde kullanılan temel analizlerden biri olan regresyon analizi, bir bağımlı (açıklanan) değişkenin, bir veya daha fazla bağımsız (açıklayıcı) değişkenle ilişkisinin matematiksel bir fonksiyonla ifade edilmesi amacı ile kullanılmaktadır. Ancak bazı deney süreçlerinde örnekteki bağımlı değişkenlerin tüm değerlerine ulaşılamaz. Bağımlı değişkenin aldığ değerler sınırlı olduğu için bazı yazarlar tarafından bu modellere "Bağımlı Değişkeni Sınırlı Modeller" adı verilmiştir. Sınırlı değişkenler olarak da adlandırılan bu tür durumlarla sıklıkla karşılaşan araştırmacılar, bu değişkenlerin sınırlanmış yapısını, sansürlenmiş (Censored) ve kırpılmış (Truncated) veriler şeklinde ikiye ayırmak zorunda kalmışlardır (Kennedy, 2006). Sınırlı bağımlı değişkenli modelleri açıklamada yaygın biçimde kullanılan Tobit model, gerek ilk kullanıcısı olan James Tobin'e ithafen, gerekse probit modele çok benzemesinden bu ismi almıştır. Tobin, ilk kez 1958 yılında dayanıklı tüketim malları üzerine hane halkı harcamalarını analiz ederken kimi ailelerin dayanıklı tüketim malı harcaması gibi bir harcama kaleminin olmaması sebebiyle bağımlı değişkeni negatif çıkan bir regresyon türü ile karşılaşmıştır. Tobin çalışmasında, harcamanın hiçbir zaman negatif olmayacağı gerçeğinden hareketle hane halkı geliri, belli bir düzeyi geçene kadar bu değişkene sıfır değeri atamıştır. O yıllarda tanımladığı bu model sansürlü regresyon modeline klasik bir örnektir (Tobin, 1958). $\mathrm{Bu}$ çalışmada kullanılan model aslında negatif olmayan bağımlı değişkenli birer doğrusal regresyon modelidir. Fiyat, ücret, harcama yaşam süresi(ömür), 
miktar, bir sistemin ya da bir makinenin dayanıklılığı... vb negatif değerler almayan değişkenler üzerine kurulu modeller literatürde 'sınırlı băğmlı dĕgişkenlí modeller olarak bir çok disiplinde yaygın olarak kullanılmaktadır.

\section{MATERYAL ve METOT}

\section{Materyal}

Bu çalışmada, Kahramanmaraş'ta Hane Halklarının Gıda Tüketim Talebi Ekonometrik Analizi konulu anket verilerinden tesadüfî olarak seçilen 200 deneğe ait veri seti kullanılmıştır (Akbay, 2005). Verilerden hareketle ailedeki fert sayısı, aile reisinin aylık geliri, kişinin eğitim düzeyi gibi bilgileri bağımsız değişken olarak kullanılarak, bu değişkenlerin kişilerin aylık balık tüketim harcaması üzerine etkisi belirlenmeye çalışılmıştır. (Koç,2013). Değişkenlerin analizinde SAS (Statistical Analysis System) paket programı kullanılmıştır (SAS, 2008). Esas olarak üç ana pencereden oluşan SAS uluslararası bir istatistiksel paket programdır (Orhan ve ark., 2004). Uygulamada kullanılan bağımlı değişken ve bağımsız değişkenler ve analiz sürecinde kullanılan kısaltılmış kodlamalar aşağıda verilmiş̧tir.

Bağımlı Değişken:

Aylık balık tüketimi için harcanan miktar(TL)/BLK

Bağımsız Değişkenler:

1-Ailedeki fert sayısı /FS

2-Aile reisinin aylık geliri(TL)/GEL

3- Kişinin eğitim düzeyi/EGT

Gölge değişken: İlköğretim mezunu olmak, lise mezunu olmak, üniversite mezunu olmak/ $\mathrm{D}_{\mathrm{i}}$

Çalışmada regresyon denklemi tahmin edildikten sonra bu denklemin gerçek değerleri ne kadar yansittığına dair model uygunluğu analizleri yapılmıştır.

Tahmin değerlerinin gerçek gözlem değerlerini ne kadar temsil ettiğinin bir ölçüsü olan belirleme katsayısı $\left(R^{2}\right)$ klasik regresyon modellerine göre sinırlı bağımlı değişkenli modellerde çok daha düşüktür (Tatoğlu, 2005). Kullanışlı bir çıkarsama yapmaya imkân tanımamasından dolayı bu modellerin analizinde $\mathrm{R}^{2}$ ' nin yerine pseudo $\mathrm{R}^{2}$ kullanılmaktadır (Eren, 2012). Bu modellerin doğruluk düzeyini test etmek için kullanılan pseudo $\mathrm{R}^{2}$ için çeşitli öneriler vardır (Tatoğlu, 2005; Joost ve Kalbermatten, 2010). Ayrıca tobit modeli de kapsayan birçok modelde modelin uygunluk ölçüsü anlamlı değildir. Bir yorum yapılmak istenirse yaklaşık bir değer olarak gözlenen değerlerle tahmin değerleri arasındaki korelasyona bakılabilir. Bununla birlikte parametrelere konan sinırlama testi de pseudo $\mathrm{R}^{2}$ ' lerin teorik aralıkları dışında kaldığı durumlarda kullanılmaktadır. Bunlar; tahmin edilen modelin gerçeği ne ölçüde tanımladığına dair elverişli ölçüler sunan Olabilirlik oranı(LR), Wald, Lagrange çarpanı(LM) testleridir. (Gujarati,1999; Chay ve Powell, 2001). 'Kısitlamaların geçerliliği testleri ya da 'parametrelere konan sinırlama testi olarak da bilinen bu testler modele hangi parametrenin alınacağı konusunda araştırıcıyı aydinlatir.

Metot

Sınırlı Bağımlı Değişkenli Modeller

Bağımlı değişkenin aldığı değerlerin sınırlı olduğu modellerle sıklıkla karşılaşan araştırmacılar, bu değişkenlerin sınırlanmış yapısını, sansürlenmiş (Censored) ve kırpılmış (Truncated) veriler şeklinde ikiye ayırmak zorunda kalmışlardır. Çünkü veri setinin kırpılması ve sansürlenmesi birbiri ile kolaylıkla karıştırılmaktadır. Dolayısıyla gerek verilerin elde edilmesi ve ardından modelin kurulması esnasında, gerekse tahmin ve çıkarsama süreçlerinde hassasiyet gösterilmelidir. Bu yüzden kimi zaman veri setinin başından, kimi zaman sonundan kimi zaman da her iki taraftan uç değerlerin kırpılması ile ortaya çıkan bu örneklem süreçlerinin analizleri için de çeşitli metotlar geliştirilmiştir. Sansürlü ve kırpılmış verileri birbirinden ayırt etmekte titizlik gösterilmelidir. Zira bu değişkenler kolayca birbirine karıştırılmaktadır. Eğer belirli bir aralığın dışındaki gözlemler tamamen kaybedilmekte ise kırpılmış (truncated) model, en azından bağımsız değişkenler gözlenebiliyorsa sansürlü (censored) model söz konusu olmaktadır (Emeç ve ark., 2001).

Yapılan araştırmada bazı veriler sistematik olarak deneyden çıkarılıyorsa oluşan model kesilmiş ya da kırpılmış model olacaktır. Kesikli modeller, belli bir oranda sinırlanmış gözlemleri olan bağımlı ve bağımsız değişkenler içeren modellerdir. Bundan dolayı bu modellere 'kırpılmış modeller' de denilmektedir. Hem bağımlı hem de bağımsız değişkenlere ait sınırlı ya da kayıp gözlemler vardır. Örneğin, çalışan hanımların ücret hadlerinin belirlenmesi için yapılan bir araştırmada veri seti, maaşları beklentilerine eşit ya da yüksek hanımlardan oluşur. Maaşları, beklentilerinin altında olan hanımlar çalışmamayı tercih edeceklerdir (Kennedy, 2006). Araba kullanma tercihi ile ilgili bir araştırmada ise örneklem 18 yaş altı için kırpılmıştır.

Sansürlenmiş örneklemde bağımsız değişken verilerinin varlığına karşın bağımlı değişkenin bazı değerlerine ulaşılamaz. Veri setinden sistematik olarak bir dışlanma söz konusu değildir ancak bağımlı değişkende gözlenemeyen kayıp veriler vardır. Örneğin et tüketiminin, gelir düzeyi ve ailedeki kişi sayısı ile ilişkisinin araştırıldığı bir çalışmada, hiç et tüketmeyen vejetaryenler için bağımsız değişken (ailedeki kişi sayısı, gelir düzeyi) değerleri mevcut iken bağımlı değişken (et tüketimi) değerleri yoktur. Bu durumda veri seti sansürlüdür. Tesadüfí olarak seçilen bir lisede, öğrencilerin sigaraya başlama yaşı ile yaşadığı yer (kent merkezi, ilçe, köy) ile ilişkisinin araştırıldığı bir araştırmada hiç sigara içmeyen öğrencilerin varlığı kaçınılmazdır. Tüm öğrencilerin bağımsız değişken olan yaşanılan yer bilgisi mevcut 
iken, bazı öğrenciler hiç sigaraya başlamadıkları için bu öğrencilere ait bağımlı değişken olan sigaraya başlama yaşı bilgisi yoktur. Bağımsız değişkenler gözleniyorken bağımlı değişkenler için veriye ulaşılamamaktadır.

\section{Sansürlenmiş Değişken Modeli (Tobit Model)}

1958 de Nobel ödüllü iktisatçı James Tobin tarafından geliştirilen, bağımlı değişkene ait bilginin yalnızca bazı gözlemler için bulunduğu sansürlü örneklem modeli olarak bilinir. En küçük kareler regresyonunun parametrik olmayan alternatifidir (Liao, 1994). Probit modelin bir uzantısı olduğundan tobin ve probit isimlerinden Tobit türetilmiştir. Model gizli bir $\mathrm{y}^{*}$ değişkenin varlığını kabul etmektedir. Bu değişken $x_{i}$ açıklayıcı değişkenine $\beta$ parametreler vektörü ile bağlıdır. Bu değişkenin dağılımı normal, ortalaması $\mu$, varyansı $\sigma^{2}$ dir. y gözlenen değişken c keyfi sansür noktası olmak üzere model, $\mathrm{u} \sim \mathrm{N}\left(0, \sigma^{2}\right)$ ve $\mathrm{y}^{*} \sim$ $\mathrm{N}\left(\mu, \sigma^{2}\right)$ varsayımlarına bağlıdır. Latent değişkenin c katsayısından büyük, küçük ya da eşit olma durumuna göre model,

$\mathrm{y}=\mathrm{c}$ eğer $\mathrm{y}^{*} \leq \mathrm{c}$ ise,

$\mathrm{y}=\mathrm{y}^{*}$ eğer $\mathrm{y}^{*}>\mathrm{c}$ ise.

şeklinde kurulur. $\mathrm{Bu}$ ifade sıfır noktasında sansürlemenin genelleştirilmiş şeklidir. Ĕger c değeri sıfıra eşitlenirse 'Standart Tobit Modelelde edilir (Carson ve Sun,2007). Genel formül ile standart tobit model latent değişkene bağlı olarak aşağıdaki gibi ifade edilir.

$\mathrm{y}=0$ eğer $\mathrm{y}^{*} \leq 0$ ise,

$\mathrm{y}=\mathrm{y}^{*}$ eğer $\mathrm{y}^{*}>0$ ise.

$y^{*}=\beta^{\prime} x_{i}+u_{i}$

Sansürlenmiş regresyon modeli kesiklilik ve süreklilik vasfını birlikte taşımaktadır. Bu değişkenler aslında birer sürekli değişkenlerdir ancak veri setinin bir kısmı hakkında gözlem sahibi olunamadığı ya da sinırlandırıldığı için, özetle sansüre tabi tutulduğundan eksik kalan gözlemlerin yerine sıfir ataması yapılmaktadır. Bundan dolayı gözlem setinin kesikli özelliğe sahip olduğu ileri sürülmektedir (Maddala,1987). Her ne kadar her iki yapıdaki (truncated, censored) bağımlı değişkenler sinırlı bağımlı değişkenler kategorisinde yer alsa da oluşturdukları örneklem farklıdır. Bu da söz konusu regresyon modelinde parametre tahminini ve çıkarımları ilgilendirmektedir.

\section{Sansürlü Normal Değişkenin Olabilirlik Fonksiyonu}

$\mathrm{Bu}$ değişkenin analizi yapılırken latent değişken $\mathrm{y}^{*}$ in yalnızca $\quad y^{*}>0 \quad$ olduğunda gözlendiği unutmamalıdır. $\mathrm{y}^{*}$ 'ın sıfıra eşit ve sıfırdan küçük olduğu durumlara sıfır ataması yapılır. Olabilirlik fonksiyonu türetilirken $\mathrm{y}^{*} \leq \mathrm{c}$ ve $\mathrm{y}^{*}>c$ olmak üzere iki aşamalı olarak düşünülmektedir. Gösterim kolaylığı sağlaması açısından $\mathrm{P}$ (sansürlü) ve $\mathrm{P}($ sansürsüz) gösterimleri kullanılacaktır. Burada, y, sürekli değişkenin olasılık yoğunluk fonksiyonu, f(y): y değişkeninin olasılık yoğunluk fonksiyonunu, c: keyfi sansür katsayısını, d: gösterge değişkenini ifade etmek üzere fonksiyon,

$$
f(y)=\left[f\left(y^{*}\right)\right]^{d_{i}}[F(c)]^{1-d_{i}}
$$

biçiminde ifade edilir. Burada d gösterge değişkeni, $\mathrm{y}>\mathrm{c}$ olduğunda 1'e eşittir. $\mathrm{d}=1$ iken y'nin yoğunluğu $\mathrm{y}>\mathrm{c}$ (sansürsüz gözlemler) için $\mathrm{y}^{*}$ ile aynıdır. $\mathrm{d}$ değişkeni $\mathrm{y}=\mathrm{c}$ olduğunda 0 'dır. $\mathrm{d}=0$ iken y'nin yoğunluğu $\mathrm{y}^{*} \leq \mathrm{c}$ nin gözlenme olasılığına eşittir. $\mathrm{y}^{*} \leq \mathrm{c}$ ve $\mathrm{y}^{*}>c$ iken olasılıklar aşağıdaki gibi olacaktır (Chay ve Powell, 2001).

$\mathrm{P}\left(\right.$ sansürlü); $\mathrm{y}^{*} \leq \mathrm{c}$ iken olasılık,

$$
\begin{gathered}
\mathrm{P}\left(\mathrm{y}_{\mathrm{i}}=\mathrm{c}\right)=\mathrm{P}\left(\mathrm{y}^{*} \leq \mathrm{c}\right)=\mathrm{P}\left(\beta^{\prime} \mathrm{x}_{\mathrm{i}}+\mathrm{u}_{\mathrm{i}} \leq \mathrm{c}\right) \\
=\mathrm{P}\left(\mathrm{u}_{\mathrm{i}} \leq \mathrm{c}-\beta^{\prime} \mathrm{x}_{\mathrm{i}}\right)=\mathrm{P}\left(\frac{\mathrm{u}_{\mathrm{i}}}{\sigma} \leq \frac{\mathrm{c}-\beta^{\prime} \mathrm{x}_{\mathrm{i}}}{\sigma}\right) \\
=\Phi\left(\frac{\mathrm{c}-\mu}{\sigma}\right)=1-\Phi\left(\frac{\mu-\mathrm{c}}{\sigma}\right)
\end{gathered}
$$

$\mathrm{P}$ (sansürsüz); $\mathrm{y}^{*}>c$ iken olasılık

$$
\mathrm{P}\left(\mathrm{y}^{*}>c\right)=1-\Phi\left(\frac{\mathrm{c}-\mu}{\sigma}\right)=\Phi\left(\frac{\mu-c}{\sigma}\right)
$$

$\mathrm{Bu}$ ifadelere göre olabilirlik fonksiyonu $\mu=\beta^{\prime} \mathrm{x}_{\mathrm{i}}$ dönüşümü yapılarak,

$$
\begin{aligned}
& \mathrm{L}=\prod_{\mathrm{i}=1}^{\mathrm{N}}\left[-\Phi\left(\frac{\beta^{\prime} \mathrm{x}_{\mathrm{i}}-\mathrm{c}}{\sigma}\right)\right]^{1-\mathrm{d}_{\mathrm{i}}}\left[\frac{1}{\sigma} \phi\left(\frac{\mathrm{y}_{\mathrm{i}}-\beta^{\prime} \mathrm{x}_{\mathrm{i}}}{\sigma}\right)\right]^{\mathrm{d}_{\mathrm{i}}} \\
& \mathrm{L}=\prod_{\mathrm{y}_{\mathrm{i}}=0}\left[1-\Phi\left(\frac{\beta^{\prime} \mathrm{x}_{\mathrm{i}}}{\sigma}\right)\right] \prod_{\mathrm{y}_{\mathrm{i}}>0} \frac{1}{\sigma} \phi\left(\frac{\mathrm{y}_{\mathrm{i}}-\beta^{\prime} \mathrm{x}_{\mathrm{i}}}{\sigma}\right) \\
& \ln \mathrm{L}=\sum_{\mathrm{y}_{\mathrm{i}}=0} \ln \left[1-\Phi\left(\frac{\beta^{\prime} \mathrm{x}_{\mathrm{i}}}{\sigma}\right)\right]+\sum_{\mathrm{y}_{\mathrm{i}}>0} \ln \frac{1}{\sigma} \phi\left(\frac{\mathrm{y}_{\mathrm{i}}-\beta^{\prime} \mathrm{x}_{\mathrm{i}}}{\sigma}\right)
\end{aligned}
$$

şeklinde formüle edilir (Park, 2003; Pettinicchi, 2012). $\operatorname{lnL}$ fonksiyonuna benzer biçimde Eşitlik 5'nin logaritması alınarak log-olabilirlik fonksiyonu da Eşitlik 7' deki gibi elde edilebilir.

$$
\begin{aligned}
& \log L=\sum_{y_{i}=0} \log \left[1-\Phi\left(\frac{\beta^{\prime} x_{i}}{\sigma}\right)\right]+\sum_{y_{i}>0}-\frac{1}{2}[\log (2 \pi)+ \\
& \left.\log \sigma^{2}+\left(\frac{y_{i}-\beta^{\prime} x_{i}}{\sigma}\right)^{2}\right]
\end{aligned}
$$

Bu oldukça karışık fonksiyon Olsen (1978)'in $\gamma=\frac{\beta}{\sigma}$ ve $\theta=\frac{1}{\sigma}$ dönüşümleri ile önemli ölçüde basitleştirilerek Eşitlik 8' deki şeklini almaktadır.

$$
\begin{gathered}
\log \mathrm{L}=\sum_{\mathrm{y}_{\mathrm{i}}>0}-\frac{1}{2}\left[\log (2 \pi)-\log \theta^{2}+\left(\theta \mathrm{y}_{\mathrm{i}}-\gamma^{\prime} \mathrm{x}_{\mathrm{i}}\right)^{2}\right]+ \\
\sum_{\mathrm{y}_{\mathrm{i}}=0} \log \left[1-\Phi\left(\gamma^{\prime} \mathrm{x}_{\mathrm{i}}\right)\right]
\end{gathered}
$$

\section{Sansürlenmiş Normal Değişkenin Momentleri}

$\mathrm{P}$ (sansürlü) ve $\mathrm{P}($ sansürsüz) olasılıklar kullanılarak beklenen değer ve varyans formülleri aşağıda verilmiştir.

$$
\begin{aligned}
& E[y]=\left\{\begin{array}{l}
P(\text { sansürsüz). } E[y \mid y>c] \\
+P(\text { sansürlü). } E[y \mid y \leq c]
\end{array}\right\} \\
& E[y]=(1-\Phi)(\mu+\sigma \lambda)+\Phi c
\end{aligned}
$$




$$
\operatorname{Var}[\mathrm{y}]=\sigma^{2}(1-\Phi)\left[(1-\delta)+(\alpha-\lambda)^{2} \Phi\right]
$$

$\mathrm{c}=0$ olduğu durumda $\mathrm{E}[\mathrm{y}]=(1-\Phi)(\mu+\sigma \lambda)$

şeklindedir.

Burada, $\Phi, \lambda, \delta$ ifadeleri, $\Phi=\Phi(\alpha)=\Phi\left(\frac{c-\mu}{\sigma}\right), \lambda=\frac{\phi}{1-\Phi}$, $\delta=\lambda^{2}-\lambda \alpha$ şeklinde tanımlanır $(\mathrm{Lu}, 2012)$.

\section{Tobit Modelde Beklenen Değer Ve Marjinal Etki}

Sigelman ve Zeng (1999)'e göre standart tobit model için üç farklı beklenen değer hesabı vardır. $\mathrm{Bu}$ beklenen değerlerden hangisinin kullanılacağ araştırıcının amacına ve veri setinin hangi kısmı ile ilgilendiğine bağlı olarak değişiklik göstermektedir. Beklenen değer hesaplamaları genellikle istatistik paket programlarının içeriğinde mevcuttur. Farklı kaynaklarda bu duruma ilişkin farklı yorumlara rastlanılmaktadır. Greene (2003, s.764) beklenen değer kavramını şu şekilde açıklamıştır:

"Bu konuda herhangi bir mutabakat sağlanılmamıştır. Yalnızca latent değişkeni temel alan araştırıcının $\mathrm{E}\left[\mathrm{y}^{*}\right]^{\prime}$ den ziyade $\mathrm{E}[\mathrm{y}]$ beklenen değerini kullanması daha kullanışlıdır."
Wooldridge (2002, s.520) ise beklenen değerlerden hangisinin kullanılacağı konusu şu şekilde ifade edilmiştir.

"Eğer araştırıcı, bağımsız değişken veya değişkenlerin, sansürlü olsun ya da olmasın açıklayıcı değişken üzerine etkisini ölçüyorsa $\mathrm{E}[\mathrm{y}]$ beklenen değerini kullanmalı, sansürlenmemiş gözlemlerle ilgileniyorsa $\mathrm{E}[\mathrm{y} \mid \mathrm{y}>0]$ formülünü kullanmalıdır.”

Çizelge 1'de beklenen değer ve marjinal etki için özet formüller verilmiştir.

\section{BULGULAR ve TARTIŞMA}

Regresyon modelinde biri nitel (üç düzeyli), ikisi nicel olmak üzere üç bağımsız değişken kullanılmıştır. Gölge değişkenler (dummy variable) olarak bilinen nitel değişkenli regresyon modellerinin genel kuralı olan "m düzeyli değişken varsa buna karşıllı m-1 tane gölge değişken kullanılır" kriteri gereğince üç düzeyli nitel EGT değişkeni için iki gölge değişken kullanılmalıdır. $\mathrm{D}_{3}$ değişkeni temel düzey olarak keyfi seçilmişstir.

Çizelge1. Beklenen değer ve marjinal etki için özet formüller

\begin{tabular}{|l|c|c|}
\hline \multicolumn{2}{|c|}{ Beklenen değer } & Marjinal etki \\
\hline latent değişken $\mathrm{y}^{*}$ için & $\mathrm{E}\left[\mathrm{y}^{*}\right]=\mathrm{X}_{\mathrm{i}} \beta$ & $\frac{\partial\left[\mathrm{y}_{\mathrm{i}}^{*} \mid \mathrm{x}_{\mathrm{i}}\right]}{\partial \mathrm{x}_{\mathrm{i}}}=\beta$ \\
\hline $\begin{array}{l}\mathrm{y} \text { tesadüfi değişkeni } \\
\text { için }\end{array}$ & $\mathrm{E}[\mathrm{y}]=\Phi\left(\frac{\mathrm{X}_{\mathrm{i}} \beta}{\sigma}\right)\left[\mathrm{X}_{\mathrm{i}} \beta+\sigma \lambda(\alpha)\right]$ & $\frac{\mathrm{E}\left[\mathrm{y}_{\mathrm{i}} \mid \mathrm{x}_{\mathrm{i}}\right]}{\partial \mathrm{x}_{\mathrm{i}}}=\beta \Phi\left(\beta^{\prime} \mathrm{x}_{\mathrm{i}} / \sigma\right)$ \\
\hline $\mathrm{y} \mid \mathrm{y}>0$ değişkeni için & $\mathrm{E}[\mathrm{y} \mid \mathrm{y}>0]=\mathrm{X}_{\mathrm{i}} \beta+\sigma \lambda(\alpha)$ & $\frac{\partial \mathrm{E}\left[\mathrm{y}_{\mathrm{i}} \mid \mathrm{x}_{\mathrm{i}} \mathrm{y}_{\mathrm{i}}>0\right]}{\partial \mathrm{x}_{\mathrm{i}}}=\beta\left\{1-\lambda\left(\frac{\beta^{\prime} \mathrm{x}_{\mathrm{i}}}{\sigma}\right)\left[\frac{\beta^{\prime} \mathrm{x}_{\mathrm{i}}}{\sigma}+\lambda\left(\frac{\beta^{\prime} \mathrm{x}_{\mathrm{i}}}{\sigma}\right)\right]\right\}$ \\
\hline
\end{tabular}

$\mathrm{Bu}$ düzey diğerlerinin karşılaştırılması için bir başvuru düzeyidir. Eğer temel kategorik değişken, örneğin, ilköğretim düzeyi olarak belirlenirse farklı gölge değişken tanımlama yoluna gidilmiş olur. Yorumlamaların değişeceğine dikkat edilmelidir.

Çalışmada temel düzeyin $\mathrm{D}_{1}$ değişseni olarak seçildiği tahmin Çizelgesi de alternatif olarak sunulmuştur. Aylık balık harcama miktarının FS, GEL, EGT değişkenlerine göre regresyonunda üç eğitim düzeyinin $\alpha_{1}, \alpha_{2}, \alpha_{3}$ şeklinde üç sabit terimi vardır. Bunlardan $\alpha_{1}, \alpha_{2}$ sirayla ilköğretim ve lise düzeyinin sabit terimleri $\alpha_{3}$ ise temel düzeyin sabit terimini ifade eder. Model şu şekilde kurulur,

$$
B L K=\alpha_{1} \mathrm{D}_{1 \mathrm{i}}+\alpha_{2} \mathrm{D}_{2 \mathrm{i}}+\alpha_{3}+\beta_{1} F S+\beta_{2} G E L+\mathrm{u}_{\mathrm{i}}
$$

Çalışmada kullanılan değişken sayıları, ortalama, standart sapma, minimum ve maksimum değerleri gibi özet istatistikler Çizelge 2' de verilmiştir.

Çalışmada gözlem sayısı 200 dür. Bunlardan 127 tanesi sansürsüz,73 tanesi soldan sansürlüdür. Verilerin derlendiği süreçte 73 gözlemde aylık balık tüketimi harcaması sıfır olarak kaydedilmiştir. Harcamada alt sınır sıfır alınarak soldan sansürleme yapılmıştır. SAS istatistik paket programında
LİFEREG Prosedürü kullanılarak bulunan analiz sonuçları Çizelge 3' de verilmiştir.

Çalışmada kullanılan bağımsız değişkenlerden kişinin eğitim durumuna ait EGT bağımsız değişkeni nitel değişkendir ve üç düzeyi vardır. Bu sebeple analiz aşamasında temel kategori, keyfi olarak sırasıyla önce üniversite mezunu olmak (Çizelge 4), sonra ilköğretim mezunu olmak (Çizelge 5) düzeyleri seçilerek parametre tahmin çizelgesi iki farklı şekilde sunulmuştur.

Çizelge 4'de parametre tahmin Çizelgesinin son satırında bulunan SCALE değeri hata varyansını temsil eder. SAS istatistik programinda sansürlü değişken analizinde kullanılan QLIM prosüdürü için bu sütun _SIGMA şeklinde görülmektedir. Çıkan sonuçlara göre fert sayısı ve eğitim bağımsız değişkenlerin katsayılarının anlamlılığını ölçmek için kullanılan ki-kare test istatistiklerinin p değeri 0.05 anlamlılık düzeyinden büyük çıkmıştır. Bu durumda bu değişkenlerin katsayılarının istatistiksel olarak anlamsız olduğu söylenebilir. Gelir değişkeninin p değeri olan 0.0193 değeri 0.05 ten düşük çıktığı için istatistiksel olarak önemli bulunmuştur. 
Çizelge 2. Tanımlayıcı istatistikler

\begin{tabular}{|l|c|c|c|c|c|c|}
\hline \multirow{2}{*}{ EGT } & Değişkenler & $\mathrm{N}$ & $\bar{X}$ & $\mathrm{~S}$ & Min & Max \\
\hline \multirow{3}{*}{ İlköğretim } & BLK & 149 & 28.71 & 37.94 & 0.00 & 280.00 \\
& FS & 149 & 4.38 & 2.09 & 1.00 & 17.00 \\
& GEL & 149 & 601.14 & 497.67 & 50.30 & 3063.00 \\
\hline \multirow{3}{*}{ Lise } & BLK & 38 & 27.68 & 33.17 & 0.00 & 135.00 \\
& FS & 38 & 4.26 & 1.81 & 2.00 & 9.00 \\
\hline \multirow{2}{*}{ Üniversite } & GEL & 38 & 761.62 & 550.38 & 261.00 & 3000 \\
& BLK & 13 & 49.42 & 111.39 & 0.00 & 415.00 \\
& FS & 13 & 3.46 & 0.52 & 3.00 & 4.00 \\
& GEL & 13 & 1127.05 & 508.60 & 514.20 & 2175.00 \\
\hline
\end{tabular}

Çizelge 3. Tobit analiz sonuçları

\begin{tabular}{|c|c|}
\hline \multicolumn{2}{|c|}{ LIFEREG Prosedürü } \\
\hline Bağımlı değişken & Balık harcaması \\
\hline Gözlem sayısı & 200 \\
\hline Sansürsüz gözlem sayısı & 127 \\
\hline Sağdan sansürlü gözlem sayısı & 0 \\
\hline Soldan sansürlü gözlem sayısı & 73 \\
\hline Log Likelihood değeri & -759.6424412 \\
\hline İterasyon sayısı & 28 \\
\hline AIC & 1531 \\
\hline Schwarz kriteri & 1551 \\
\hline
\end{tabular}

Çizelge 4. Parametre tahmini (1)(Temel düzey: Üniversite mezunu)

\begin{tabular}{|c|c|c|c|c|c|c|c|c|}
\hline PARAMETRE & \multicolumn{2}{|c|}{$\mathrm{sd}$} & $\beta$ & $S$ & \multicolumn{2}{|c|}{ 95\% Güven aralıkları } & Ki-Kare & $\mathrm{Pr}>\mathrm{Ki}$-Kare \\
\hline SABİT & & 1 & 10.5622 & 21.6416 & -31.8546 & 52.9789 & 0.24 & 0.6255 \\
\hline FS & & 1 & 0.8554 & 2.4062 & -3.8607 & 5.5715 & 0.13 & 0.7222 \\
\hline GEL & & 1 & 0.0213 & 0.0091 & -0.0035 & 0.0392 & 5.48 & $0.0193^{*}$ \\
\hline EGT & $\mathrm{D}_{1}$ & 1 & -14.6929 & 19.3625 & -52.6427 & 23.2569 & 0.58 & 0.4480 \\
\hline EGT & $\mathrm{D}_{2}$ & 1 & -20.7474 & 21.0797 & -62.0629 & 20.5680 & 0.97 & 0.3250 \\
\hline EGT & $\mathrm{D}_{3}$ & 0 & 0.0000 & & & & & . \\
\hline SCALE & & 1 & 61.2757 & 4.1047 & 53.7364 & 69.8728 & & \\
\hline
\end{tabular}

Çizelge 5. Parametre tahmini (2)(Temel düzey: İlköğretim mezunu)

\begin{tabular}{|c|c|c|c|c|c|c|}
\hline \multirow{2}{*}{ PARAMETRE } & \multicolumn{2}{|c|}{$\mathrm{sd}$} & $\beta$ & $\mathrm{S}$ & $\mathrm{t}$ & $\operatorname{Pr}>\mathrm{t}$ \\
\hline SABİT & & 1 & -4.1306 & 12.5220 & -0.33 & 0.7415 \\
\hline FS & & 1 & 0.8554 & 2.4062 & 0.36 & 0.7222 \\
\hline GEL & & 1 & 0.0213 & 0.0091 & 2.34 & $0.0193^{*}$ \\
\hline EGT & $\mathrm{D}_{1}$ & 0 & 0 &. &. &. \\
\hline EGT & $\mathrm{D}_{2}$ & 1 & -6.0545 & 21.0338 & -0.50 & 0.6149 \\
\hline EGT & $\mathrm{D}_{3}$ & 1 & 14.6928 & 19.3624 & 0.76 & 0.4480 \\
\hline SİGMA & & 1 & 61.2757 & 4.1047 & 14.93 & $<.0001$ \\
\hline
\end{tabular}

Çizelge 4'deki katsayılar kullanılarak oluşturulan model,

$\mathrm{E}(\mathrm{Y} \mid \mathrm{X})=10.5622+0.8554 \mathrm{FS}+0.0213 \mathrm{GEL}-$ $14.6929\left(D_{1}\right)-20.7474\left(D_{2}\right)$

şeklinde ifade edilebilir. Bu katsayıların önem testi klasik yollarla yapılabilir. Sonuçların yorumlanması ise EKK regresyonun yorumuna benzerdir.

Örneğin, ailedeki fert sayısındaki bir birimlik artış diğer değişkenlerin sabit tutulması halinde balık tüketimi harcama miktarında 0,8554 lık artışa sebep olur. Gelir değişkenindeki bir birimlik artış ise balık tüketimi harcama miktarında 0,0213 lik artışa sebep olur. Bütün değişkenler sabit tutulduğunda ise kişilerin aylık balık harcama miktarları ortalama 10-
11TL civarında olması beklenmektedir.

Eğitim değişkenin yorumu diğer nicel değişkenlerden farklıdır. Bu değişken üç düzeyi bulunan nitel bir değişkendir. Çalışmada üniversite değişkeni temel düzey olarak alınmıştır. Bu da nitel değişken yorumu sırasında araştırıcıya bir kıyas kolaylığı sağlar. Örneğin eğitim değişkeninin düzeylerinden biri olan ilköğretim mezunu olmak düzeyinin katsayısı -14,6929 dur. Tüm değişkenler sabit tutularak bir ilköğretim mezunu olan kişinin aylık balık harcama miktarı üniversite mezunu olan bir başkasından 4,1307 TL ( 10,5622-14,6929=-4,1307 ) daha azdır. Eğitim değişkenin diğer düzeyi lise mezunu olmak düzeyinin katsayısı ise -20,7474 TL dir. Tüm değişkenler sabit 
tutularak bir lise mezunu olan kişinin aylık balık harcama miktarları üniversite mezunu olan bir başkasından 10,1852 TL (10,5622-20,7474=-10,1852 ) daha azdır. İlköğretim mezunu olmak temel düzey değişkeni olarak alınsaydı parametrelerin katsayıları, bu katsayılara ilişkin $\mathrm{p}$ değerlerinin değişeceği kaçınılmazdı. Bu çalışmada araştırıcıya bir alternatif sunmak amaciyla temel düzey ilköğretim mezunu alınarak yapılan parametre tahmin çizelgesi de Çizelge 5'de verilmiştir. Çizelge 5'de tahmin edilen parametreler ile model kurulup katsayılar yerine koyulduğunda aynı sonuçların çıkması beklenir.

Çizelge 5' de çıkan sonuçlara göre katsayıların anlamlılığını ölçmek için kullanılan $\mathrm{t}$ testi istatistiğinin $\mathrm{p}$ değeri fert sayısı ve eğitim değişkeni için $\alpha=0.05$ anlamlllık düzeyinde istatistiksel olarak önemsiz, gelir değişkeni ise $\mathrm{a}=0.05$ anlamlılık düzeyinde istatistiksel olarak önemli çıkmıştır.

$\mathrm{Bu}$ katsayıları kullanılarak oluşturulan model,

$$
\begin{array}{r}
\mathrm{E}(\mathrm{Y} \mid \mathrm{X})=-4.1306+0.8554 \mathrm{xFS}+0.0213 \mathrm{xGEL} \\
-6.0545 \mathrm{x}\left(\mathrm{D}_{2}\right)-146928 \mathrm{x}\left(\mathrm{D}_{3}\right)
\end{array}
$$

şeklindedir. Eğitim değişkenin diğer düzeyi lise mezunu olmak düzeyinin katsayısı -6.0545 TL dir. Tüm değişkenler sabit tutularak bir lise mezunu olan kişinin aylık balık harcama miktarları üniversite mezunu olan bir başkasından 10,1851 TL (-4.1306$6.0545=-10,1851$ ) daha azdır. Bu yorum Çizelge 4 kullanılarak bulunan sonuçla hemen hemen aynıdır.

Modelin tahmininden sonra uyum iyiliği ölçülerine bakılmıştır. Bağımlı değişkenin nitel olduğu analizlerde belirlilik katsayısının değeri oldukça düşük çıkmaktadır. $\mathrm{Bu}$ nedenle, bu modellerde $\mathrm{R}^{2}$ yerine pseudo $\mathrm{R}^{2}$ kullanılmaktadır. $\mathrm{Bu}$ pseudo $\mathrm{R}^{2}$ değerleri alışılmış $R^{2}$ değerlerinden farklıdır ve 0 ile 1 arasında yer almayabilir. Bu durumun nedeni modelin olabilirlik süreci ile tahmin edilmesinden kaynaklanmaktır. Dolayısıyla belirlilik katsayısının negatif ya da birden büyük değer alması yadırganılacak bir durum değildir (Maddala, 1987; Kennedy, 2006). Çalışmada modelin uygunluk ölçüsünün yorumlanması adına Akaike bilgi kriteri, Schwarz kriterinin yanı sıra Tobit model için önerilen çeşitli pseudo $\mathrm{R}^{2}$ değerleri hesaplanmış alternatif olarak gözlenen değerlerle tahmin edilen değerler arasındaki korelasyona da bakılmıştır (Çizelge 6). Bunun yanı sira parametrelerin tek tek ve birlikte kısitlılık testleri Wald, LR ve LM testleri ile analiz edilmiştir. Sonuçlar sırasıyla Çizelge 7, Çizelge 8, Çizelge 9'da verilmişstir.

Çizelge 6. Gözlenen ve tahmin edilen harcama arasındaki korelasyon

\begin{tabular}{|c|c|c|}
\hline Değisken adı & Tahmini balık harcaması & P değeri \\
\hline Balık harcaması & $0.248^{* * *}$ & 0.0004 \\
\hline
\end{tabular}

\begin{tabular}{|c|c|c|c|c|}
\hline Sinırlama & Model & Test adı & Test istatistiği & $\mathrm{P}$ \\
\hline \multirow{3}{*}{ Fert sayısı $=0$} & \multirow{3}{*}{$\hat{y}=\widehat{b_{0}}+\widehat{\text { gel }} x_{2}+\widehat{\text { egtx }} x_{3}$} & WALD & $72.88^{* * *}$ & $<.0001$ \\
\hline & & LR & 0.00 & 0.9821 \\
\hline & & LM & $4.99^{* * *}$ & $<.0001$ \\
\hline
\end{tabular}

Çizelge 7. Kısıtlamaların geçerliliği testi (1)

\begin{tabular}{|c|c|c|c|c|}
\hline Sinırlama & Model & Test adı & Test istatistiği & $\mathrm{P}$ \\
\hline \multirow{3}{*}{ Gelir $=0$} & \multirow{3}{*}{$\hat{y}=\widehat{b_{0}}+\widehat{f s} x_{1}+\widehat{e g t x} x_{3}$} & WALD & . & . \\
\hline & & LR & 0.00 & 0.9609 \\
\hline & & LM & $834 \mathrm{E}-14^{* * *}$ & $<.0001$ \\
\hline
\end{tabular}

Çizelge 8. Kısıtlamaların geçerliliği testi (2)

Çizelge 9. Kısıtlamaların geçerliliği testi (3)

\begin{tabular}{|c|c|c|c|c|}
\hline Sinırlama & Model & Test adı & Test istatistiği & P \\
\hline \multirow{2}{*}{ Egt $=0$} & \multirow{3}{*}{$\hat{\mathrm{y}}=\widehat{\mathrm{b}}_{0}+\widehat{\mathrm{fsx}}_{1}+\widehat{\operatorname{gel}}_{2}$} & WALD & $72.88^{* * * *}$ & $<.0001$ \\
\cline { 3 - 5 } & & LR & 0.00 & 0.9791 \\
\cline { 2 - 4 } & LM & 0.00 & 1.0000 \\
\hline
\end{tabular}

\begin{tabular}{|c|c|c|c|c|}
\hline Sinırlama & Model & Test adı & Test istatistiği & P değeri \\
\hline \multirow{3}{*}{$\mathrm{fs}=0$, gel $=0$} & \multirow{3}{*}{$\hat{y}=\widehat{b_{0}}+\widehat{e g t x} x_{3}$} & WALD & $3470.3^{* * *}$ & $<.0001$ \\
\hline & & LR & 0.01 & 0.9970 \\
\hline & & LM & $838 \mathrm{E}-14^{* * *}$ & $<.0001$ \\
\hline \multirow{3}{*}{$\mathrm{fs}=0, \mathrm{egt}=0$} & \multirow{3}{*}{$\hat{y}=\widehat{b_{0}}+\widehat{\text { gel }} x_{2}$} & WALD & . & . \\
\hline & & LR & 0.00 & 0.9988 \\
\hline & & LM & $5.06 \mathrm{E}-8^{* * *}$ & $<.0001$ \\
\hline \multirow{2}{*}{ gel $=0$,egt $=0$} & \multirow{2}{*}{$\hat{y}=\widehat{b_{0}}+\widehat{e g t x} x_{3}$} & WALD & . & . \\
\hline & & LR & 0.01 & 0.9969 \\
\hline
\end{tabular}

Çizelge 10. Kısıtlamaların geçerliliği testi (4) 


\begin{tabular}{|l|l|l|l|l|}
\hline & & LM & $84 \mathrm{E}-15^{* * *}$ & $<.0001$ \\
\hline
\end{tabular}

Gözlenen değerlerle tahmin edilen değerler arasındaki korelasyon 0.248 bulunmuştur $(\mathrm{p}<0.001)$. Bu değerin karesi $0.248^{2}=0.0615$ tir. Bu değere bakıldığında modelde tüm bağımsız değişkenler beraberce, bağımlı değişkendeki değişkenliğin \%6'sını açıklamaktadır. Bağımsız değişkenlerin bağımlı değişkeni açıklama gücü olarak ifade edilen belirleme katsayısı için $\% 6{ }^{\prime} l ı k$ bir değer düşük bir düzeydir.

Wald ve LM test istatistiklerinin olasılık değerleri çok küçük çıkmıştır. $\mathrm{Bu}$ durumda $\mathrm{H}_{0}$ hipotezi reddedilir. $\mathrm{Bu}$ testlere göre fert sayısı değişkeni modelde bulunmalıdır. Sinırlama geçersizdir. LR test istatistiğinin olasılık değeri istatistiksel olarak anlamlı bulunmamıştır. Modele getirtilebilecek farklı sınırlama çeşitleri ve hipotezleri aşağıdaki gibi açıklanmaya çalışılmıştır.

Gelir değişkenine getirilen sınırlama, LR, Wald ve LM testleri ile sinanmıştır (Çizelge 8).

Çizelge 8' den LM test istatistiğinin olasılık değeri istatistiksel olarak anlaml bulunmuştur. Yani $\mathrm{H}_{0}$ hipotezi LM testine göre reddedilir. Gelir değişkenine uygulanan sinırlama LM testine göre geçersizdir.

Eğitim değişkenine getirilen sinırlama LR, Wald ve LM testleri ile sınanmıştır (Çizelge 9)

Wald test istatistiğinin olasılık değeri istatistiksel olarak önemli bulunmuştur $(\mathrm{P}<0.001)$. Yani $\mathrm{H}_{0}$ hipotezi Wald testine göre reddedilir. Eğitim değişkenine uygulanan sinırlama Wald testine göre geçersizdir.

Fert sayısı - gelir, fert sayısı-eğitim ve gelir-eğitim değişken birleşimlerine getirilen sınırlamalar Çizelge 10'da toplu olarak verilmiştir.

$\mathrm{Bu}$ sonuçlara göre; fert sayısı ve gelir değişkenine getirilen sinırlama Wald ve LM test sonuçlarına göre geçersizdir. Yani bu testlere göre değişkenler modele katılmalıdır. Fert sayısı ve eğitim değişkenine getirilen sinırlamalar LM test sonuçlarına göre geçersizdir. Bu sonuçtan hareketle fert sayısı ve eğitim değişkeni beraberce bağımlı değişkeni açıklamada istatistiksel olarak anlamlıdır, modele alınmalıdır denilebilir. Gelir ve eğitim değişkenine getirilen sinırlamalar da LM test sonuçlarına göre geçersizdir. Burada da aynı şekilde bu değişkenlerin modele katılması gerektiği sonucuna varılabilir.

\section{SONUÇ}

Sonuç olarak, yaşam analizi, ömür modellemeleri, makinelerin bozulma süreleri, tüketim harcamaları gibi bağımlı değişkenin negatif olmadığı deneylerin parametre tahminlerinde Tobit Regresyon Analizini kullanmak araştırıcıyı etkin sonuçlara götürür. Hazırlanan bu çalışma ile analizlerinde sürekli ve kesikli verilerin karma yapısı ile karşılaşan araştırıcılara istatistiksel çıkarsama sürecine yardımcı bilgiler sunulmuştur.
Ayrıca, incelenen Türkçe kaynaklarda modelin analiz basamakları hakkında çok fazla bilgiye rastlanılmaması, teorik ve pratik bilgiye beraberce ulaşılamaması ve yapılan araştırmalarda konunun ayrıntısından ziyade sadece sonuçlarına yer verilmesi söz konusudur. Geleceğe yönelik olarak araştırıcıların, eserlerinde bu konulara yer vermeleri Türkiye'deki istatistik biliminin gelişmesine katkıda bulunacaktır.

\section{KAYNAKLAR}

Akbay C 2005. Kahramanmaraş'ta Hane halklarının Gida Tüketim Talebi Ekonometrik Analizi. KSÜ Fen ve Mühendislik Dergisi, 8(1): 114-121.

Carson RT, Sun Y 2007. The Tobit model with a nonzero threshold. Econometrics Journal,10: 488-502.

Chay YK, Powell LJ 2001. Semiparametric Censored Regression Model. Journal of Economic Perspectives, American Economic Association, 15(4): 29-42.

Orhan H, Efe E, Şahin M 2004. SAS Yazılımı İle İstatistiksel Analizler. Tuğra Ofset, ISBN:975-270435-2, Isparta, 122s.

Emeç H, Üçdoğruk Ş, Akın F, 2001. Türkiye Hanehalkı Eğlence Kültür Harcamalarında Tobit Modelin Kullanımı. G.Ü. İ.İ.B.F Dergisi, (3):13-26.

Eren M 2012. Sinırlı Bağımlı Değişkenli Modeller Ve Ülkelerin Gelişmişlik Düzeyleri Üzerine Uygulama. Atatürk Üniversitesi Sosyal Bilimler Enstitüsü, Ekonometri, Erzurum, Yüksek Lisans Tezi, 68s

Gujarati DN 1999. Temel Ekonometri, Çevirenler: Ümit Şenesen-G.Günlük Şenesen, Litaratür Yayınları No:33, İstanbul, 848s

Greene HW 2003. Econometric Analysis. Prentise Hall, ISBN: 01306 61899, New Jersey, 1026s.

Joost S, Kalbermatten M 2010. MatSAM versiyon 2 Beta http://www.econogene.eu/software /sam/ download/matsamv2/MatSAMv2_documentation.p df (erişim tarihi: 02.03.2013)

Kennedy P 2006. Ekonometri Kılavuzu, Çevirenler: Muzaffer Sarımeşeli-Şenay Açıkgöz, Gazi Kitapevi, Ankara, 754s.

Koç S 2013. Tobit Regresyon Analizi Ve Bir Uygulama. KSÜ Fen Bilimleri Enstitüsü, Zootekni, K.Maraş, Yüksek Lisans Tezi,57s.

Liao TF 1994. Interpreting Probability Models: Logit, Probit, And Other Generalized Linear Models. Sage Publications ,California, 87s.

Maddala GS 1987. Limited Dependent and Qualitative Variables in Econometrics. Cambridge University Press, Cambridge, 1004s.

Olsen RJ 1978. Note on the Uniqueness of the Maximum Likelihood Estimator for the Tobit Model. Econometrica, 46(5): 1211-1215

Park SY 2003. Unbiasedness or Statistical Efficiency: Comparison between One-stage Tobit of MLE and 
Two-step Tobit of OLS. International Journal of Human Ecology, 4(2): 77-86.

Pettinicchi Y 2012. Emprical Economics. http://www.virgo.unive.it/ypetti/Lecture3_Pettinicc hi.pdf (erişim tarihi: 7.11.2012)

SAS, 2008. SISITEINFO NAME='VAN 100.YIL UNIVERSITESI' TE $=93053001$

Sigelman L, Zeng L 1999. Analyzing Censored and Sample-Selected Data with Tobit and Heckit Models. Political Analysis, 8 (2): 167-182.
Tatoğlu FY 2005. Sermaye Piyasası'nda Riskin Sınırlı Bağımlı Değişkenli Panel Veri Modelleri Ile Analizi. İstanbul Üniversitesi Sosyal Bilimler Enstitüsü, Ekonometri, İstanbul, Doktora Tezi, 199s.

Tobin J 1958. Estimation of Relationships for Limited Dependent Variables. Econometrica, 46(1): 24-36.

Wooldridge J 2002. Econometric Analysis of Cross Section and Panel Data. MIT Press, Cambridge, $735 \mathrm{~s}$ 